E3S Web of Conferences 1, 39003 (2013)

DOI: $10.1051 / \mathrm{e} 3$ sconf/20130139003

(C) Owned by the authors, published by EDP Sciences, 2013

\title{
Speciation analysis of arsenic compounds in the serum and urine of a patient with acute arsine poisoning
}

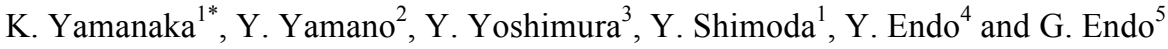 \\ ${ }^{1}$ Laboratory of Environmental Toxicology and Carcinogenesis, Nihon University School of Pharmacy, Funabashi, Chiba \\ 274-8555, JAPAN, yamanaka.kenzo@nihon-u.ac.jp \\ ${ }^{2}$ Department of Hygiene and Preventive Medicine, Showa University, School of Medicine, Tokyo, 142-8555, JAPAN, \\ yamano@med.showa-u.ac.jp \\ ${ }^{3}$ Department of Infectious Disease, Yokohama Municipal Citizen’s Hospital, Yokohama 240-8555, JAPAN, \\ yy_mole@yahoo.co.jpet \\ ${ }^{4}$ Research Center for Occupational Poisoning, Kansai Rosai Hospital, Japan Labour Health and Welfare Organization, \\ Amagasaki 660-8511, JAPAN, yokoendo@kanrou.np \\ ${ }^{5}$ Department of Preventive Medicine and Environmental Health, Graduate School of Medicine, Osaka City University, \\ Osaka 545-8585, JAPAN, endog@med.osaka-cu.ac.jp
}

\begin{abstract}
Arsine is one of the most potent hemolytic agents. It is important to clarify arsine metabolism as well as its chemical interactions with biological components. The aim of the present study was to clarify arsine metabolism by arsenic speciation analysis in serum and urine from an acute poisoning patient with hematuria, anemia, and renal and liver dysfunction. Speciation analysis of arsenics in serum and urine was performed using HPLC-ICP-MS. The total arsenic (T-As) concentration in serum was $244.8 \mu \mathrm{g} / 1$ at admission and 97.1 $\mu \mathrm{g} / 1$ at discharge. In the speciation analysis, four kinds of As compounds derived from arsine metabolism were detected in serum and urine. The concentration of arsenite (AsIII), arsenate (AsV), monomethylarsonic acid (MMA), and dimethylarsinic acid (DMA) in serum at admission were 45.8, 5.2, 17.9 and $9.3 \mu \mathrm{g} / 1$, respectively. The concentrations of AsIII, AsV, and MMA decreased with biological half time (BHT) of 30.1, 43.0, and 96.3 $\mathrm{h}$, respectively. Only DMA was increased at discharge. The urinary AsIII, AsV, MMA and DMA concentrations were 223.0, 12.1, 317.5 and $1053.5 \mu \mathrm{g} / 1$ at discharge, and decreased with BHT of 15.1, 20.8, 14.7, and $16.0 \mathrm{~d}$, respectively. The results indicate that arsine was quickly metabolized to AsIII and subsequently up to DMA, with the result that the toxic effects of inorganic arsenic were added to those of arsine toxicity.
\end{abstract}

Key words: Acute poisoning, arsine, blood, speciation analysis

\section{Introduction}

Arsine $\left(\mathrm{AsH}_{3}\right)$ is one of the most potent hemolytic agents, and is used extensively in the semiconductor industries. Although the mechanism of arsine toxicity is not clearly understood, hemoglobin $(\mathrm{Hb})$ has long been recognized as a necessary component of the overall mechanism of arsine induced hemolysis. In order to clarify the mechanism of arsine toxicity, studies of the differences between arsenic trioxide metabolism and arsine metabolism are necessary. However, reports concerning the metabolism of arsine in animals and humans are rare. Apostoli et al. (1997) reported metabolites of inorganic trivalent As (AsIII), such as arsenate (AsV), monomethylarsonic acid (MMA), and dimethylarsinic acid (DMA) were detected in the urine of an acute arsine poisoning patient, and MMA was excreted mostly via the urine for $24 \mathrm{~d}$. However, arsenic species in the blood and serum of the patient were not analyzed. In the present study, we describe arsine metabolism using speciation 
analysis of arsenic compounds in the serum and urine of an acute arsine poisoning patient.

\section{Materials and Methods}

An employee of a gallium arsenide (GaAs) recycling factory was admitted to hospital because of hematuria and vomiting. Clinical laboratory examinations of blood and urine were performed by routine methods. Total As and $\mathrm{Ga}$ in serum were determined by Agilent 7500cx ICP-MS using $\mathrm{He}$ as a collision gas. The limits of detection for As and $\mathrm{Ga}$ were 0.005 and $0.007 \mu \mathrm{g} / \mathrm{l}$, respectively. Arsenic speciation analysis was performed using two separation modes of anion (IonPac AS22, $250 \times 4.0 \mathrm{~mm}$ i.d., Dionex, USA) and cation (RSpak NN-614, $150 \times 6.0 \mathrm{~mm}$ i.d., Showa Denko, Japan) exchange columns. Fifty microliters of serum was mixed with $450 \mu 1$ of ultra-pure water and filtrated using a Microcon YM-10 by centrifugation at $12,000 \mathrm{rpm}$ for $30 \mathrm{~min}$. Fifty microliters of the ultrafiltrate was run on into the HPLC system. The recovery rates for AsIII, AsV, MMA, DMA and arsenobetaine (AsBe) by Microcon filtration when serum samples $(\mathrm{n}=3)$ were spiked at $10 \mu \mathrm{g} / \mathrm{l}$ for each As compound were 99, 106, 104, 103 and 105\%, respectively. Urine was diluted 10 times with ultra-pure water. Fifty microliters of the diluted urine sample was injected into the HPLC-ICP-MS.

\section{Results and Discussion}

The clinical laboratory values of the patient at the time of admission are described in Table 1. Hemolytic anemia and renal and liver dysfunction were observed, but all other physical findings were normal. The time course changes in serum hemoglobin and urinalysis are shown in Fig. 1. It was reported that arsine exposure causes hemoglobinuria but not erythrocyturia (Hesdorffer et al., 1986). In acute inorganic arsenic poisoning, erythrocyturia but not hemoglobinuria was found (Dakeishi et al., 2006). In our case, not only occult blood but also significant amounts of RBC were detected in urine. At that time, AsIII was detected in his serum as described below, meaning arsine is rapidly converted to AsIII. These results suggest that both arsine toxicity and AsIII toxicity are involved in arsine poisoning.

The total As (T-As) and Ga in the serum of the patient were 244.8 and $<0.14 \mu \mathrm{g} / 1$ at admission (34 $\mathrm{h}$ after the accidental exposure) and 97.1 and $0.59 \mu \mathrm{g} / 1$ on day 5 (112 h). A significant decrease in the T-As concentration with time was found and the biological half time (BHT) was estimated to be $59.2 \mathrm{~h}$. Apostoli et al (1997) reported that the BHT of T-As in the blood of a patient with acute arsine poisoning followed a triphasic model with periods of $28 \mathrm{~h}, 59 \mathrm{~h}$, and 9 days. Our estimated BHT of T-As in serum agrees very well with their second-phase BHT of T-As in blood. The T-As at 110 days after the accident
Table 1. Clinical laboratory tests results at the admission

\begin{tabular}{|c|c|c|c|}
\hline & Test (unit) & Value & \\
\hline \multirow{5}{*}{$\begin{array}{l}\frac{D}{0} \\
\frac{0}{n}\end{array}$} & $\mathrm{RBC}\left(\times 10^{4} / \mu \mathrm{l}\right)$ & 249 & $\downarrow \downarrow$ \\
\hline & WBC $(/ \mu 1)$ & 14300 & $\uparrow$ \\
\hline & $\mathrm{Hb}(\mathrm{g} / \mathrm{dl})$ & 9.1 & $\downarrow \downarrow$ \\
\hline & $\operatorname{MCV}(f l)$ & 108 & $\uparrow$ \\
\hline & Platelet $\left(\times 10^{4} / \mu 1\right)$ & 20.3 & \\
\hline \multirow{10}{*}{$\begin{array}{l}\Xi \\
\stackrel{\Xi}{0} \\
\stackrel{D}{\infty}\end{array}$} & T-Bil (mg/dl) & 8.1 & $\uparrow \uparrow$ \\
\hline & $\mathrm{TP}(\mathrm{g} / \mathrm{dl})$ & 6.8 & \\
\hline & $\gamma-\mathrm{GT}(\mathrm{IU} / \mathrm{l})$ & 81 & $\uparrow$ \\
\hline & AST (IU/1) & 560 & $\uparrow \uparrow$ \\
\hline & ALT $\quad(\mathrm{IU} / 1)$ & 105 & $\uparrow \uparrow$ \\
\hline & LDH $\quad(\mathrm{IU} / \mathrm{l})$ & 4405 & $\uparrow \uparrow$ \\
\hline & Creatinine $(\mathrm{mg} / \mathrm{dl})$ & 1.33 & $\uparrow$ \\
\hline & BUN $\quad(\mathrm{mg} / \mathrm{dl})$ & 39.8 & $\uparrow$ \\
\hline & $\mathrm{CK}(\mathrm{IU} / 1)$ & 406 & $\uparrow \uparrow$ \\
\hline & CRP (mg/dl) & 7.0 & $\uparrow \uparrow$ \\
\hline \multirow{4}{*}{$\stackrel{\mathscr{\Xi}}{\Xi}$} & Protein & + & $\uparrow$ \\
\hline & RBC (/HPF) & $>100$ & $\uparrow \uparrow$ \\
\hline & WBC (/HPF) & $1-4$ & \\
\hline & Occult blood & $4+$ & $\uparrow \uparrow$ \\
\hline
\end{tabular}

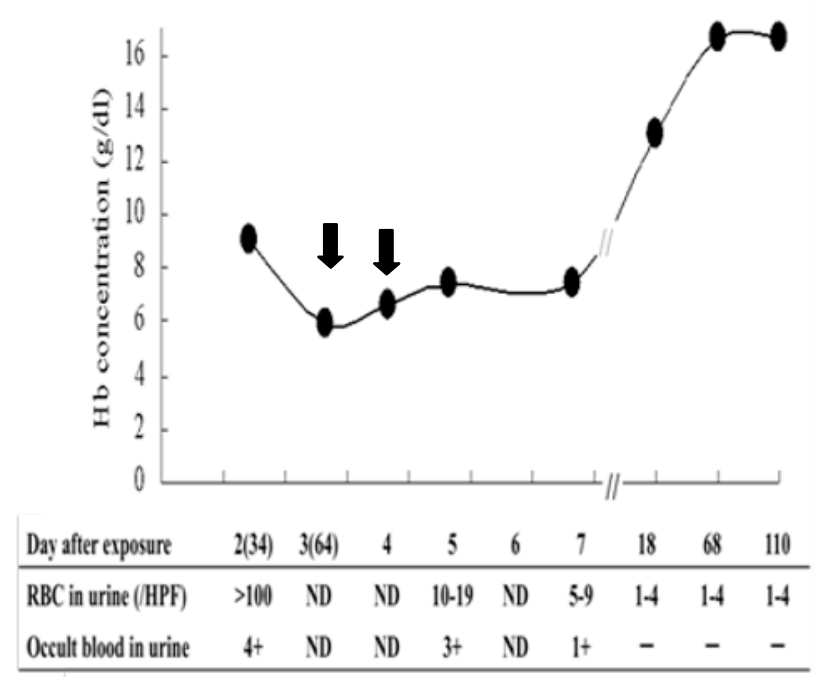

Fig. 1. Time course changes in hemoglobin concentration and urinalysis. The values in parenthesis indicate hours. ND: not determined. $\downarrow$ : two units of packed red blood cells were transfused daily for 2 days.

was $1.5 \mu \mathrm{g} / 1$.

Four kinds of As compounds derived from arsine metabolism and $\mathrm{AsBe}$ were detected in both serum and urine.

We did not detect other forms of As compounds in the serum as shown in Fig. 2, though the analyses were performed using two kinds of different columns. The concentrations of AsIII, AsV, MMA, DMA and AsBe in serum at admission were 45.8, 5.2, 17.9, 9.3, and $3.4 \mu \mathrm{g} / 1$, respectively. The highest concentration of an arsenic 


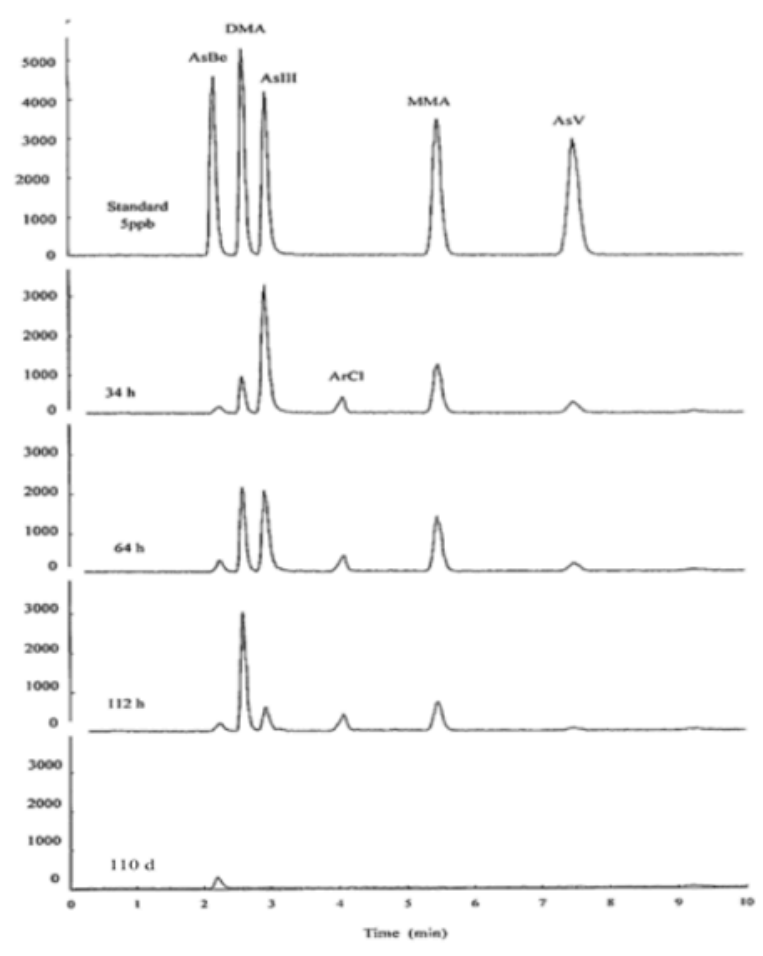

Fig. 2. Chromatograms obtained by HPLC-ICP-MS of a standard solution and three serum samples collected 34 , 65 , and $112 \mathrm{~h}$ after the arsine exposure.

compound was AsIII at $34 \mathrm{~h}$ and DMA at $112 \mathrm{~h}$. The changes in As species concentrations in serum during hospitalization are shown in Fig. 3. The BHT of AsIII, $\mathrm{AsV}$, and MMA were estimated to be 30.1, 43.0, and 96.3 $\mathrm{h}$, respectively. Only DMA increased with time during the 6-day hospitalization so its BHT could not be calculated. Apostoli et al. (1997) reported that the elimination of AsIII proceeded as an exponentially decreasing curve and that of MMA was observed early even on day1, while that of DMA increased progressively and culminated on day 5 after arsine intoxication. They estimated the BHTs of AsIII, AsV, MMA, and DMA using urinary concentrations to be 57.11, 27.01, 56.29, and $71.80 \mathrm{~h}$, respectively. Our results indicated arsine is quickly changed to AsIII and then metabolized to DMA in the human body. The AsBe concentration was almost constant throughout his hospitalization. Only AsBe was detected in the serum 110 days later. AsBe is frequently ingested by humans via the consumption of seafood and excreted unchanged in urine (Le et al., 1994), therefore, the concentration is the highest among As compounds in the urine of ordinary Japanese (Suzuki et al., 2009). On the contrary, the concentration of AsBe in the serum and urine of the patient were very low during admission and at the time of discharge because he had IVH during hospitalization while fasting.

The arsenic compounds detected in the serum of our patient were considered to be not bound with protein because they were detected in the extract treated with a filtration cut-off of molecular weight 10,000. A slight decrease was found in the sum of the concentrations of the four As species, expressed as extracted As (E-As), and the BHT was $115.5 \mathrm{~h}$. When a human blood sample was exposed to arsine vapor for $90 \mathrm{~min}$ at room temperature, partial hemolysis was observed, and AsIII and As-adduct were detected in the plasma. However, after ultrafiltration using a cut-off of $10 \mathrm{kDa}$, the As-adduct derived from erythrocytes was not detected in the filtrate (Higashikawa et al., 2008). AsIII and erythrocyte constituents are not involved in the production of As-adduct (Higashikawa et al., 2008). In our case, we did not detect As-adduct after ultrafiltration with a $10 \mathrm{kDa}$ cut-off level, however, the ratio of E-As to $\mathrm{T}$-As increased with time from $33.3 \%$ at $34 \mathrm{~h}$ to $53.5 \%$ at $112 \mathrm{~h}$. On the contrary, constant E-As/T-As ratios were observed in the blood of a patient with acute promyelocytic leukemia (APL) after remission induction therapy using AsIII (Yoshino et al., 2009). Since our patient had hemolytic anemia, T-As in his serum sampled at $34 \mathrm{~h}$ after the accidental exposure may contain As-adduct bound to hemoglobin. Thus, the E-As/T-As ratio in our patient was different from that in the patient exposed to inorganic arsenic. This may be the characteristic metabolic profile of arsine poisoning.

Since the As concentrations in the urine collected during hospitalization were not analyzed, the urine analyzed was first sampled 6 days after the accident. The changes in the urinary arsenic concentrations are described in Fig. 4. The urinary AsIII, AsV, MMA, DMA, and $\mathrm{AsBe}$ concentrations on the day before discharge were 223.0, 12.1, 317.5, 1053.5, and $1.1 \mu \mathrm{g} / \mathrm{l}$, respectively.

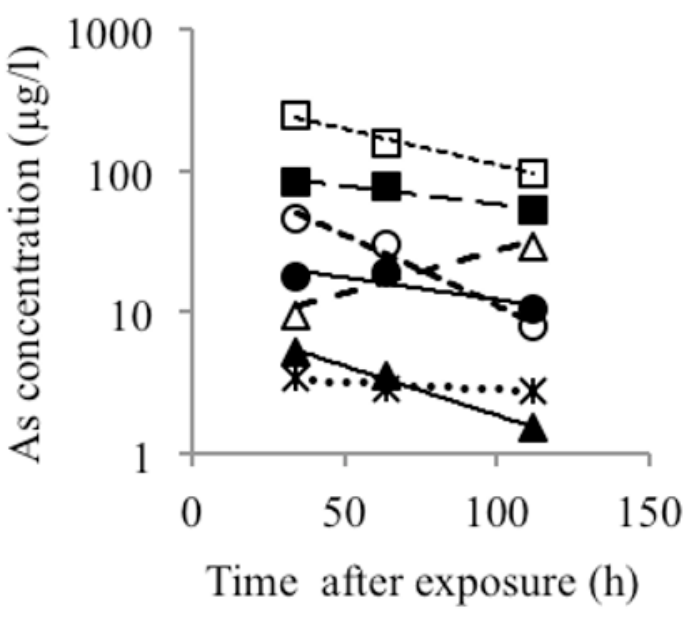

Fig. 3. Changes of arsenic species concentration in serum during hospitalization.

$\mathrm{AsV}, \boldsymbol{\Delta}, \mathrm{y}=9.292 \mathrm{e}^{0.161 \mathrm{x}}\left(\mathrm{R}^{2}=0.995\right)$; AsIII, o, $\mathrm{y}=110.06 \mathrm{e}^{-0.0230 \mathrm{x}}\left(\mathrm{R}^{2}=0.978\right) ;$ MMA, $\bullet, \mathrm{y}=25.36 \mathrm{e}^{-0.00721 \mathrm{x}}$ $\left(\mathrm{R}^{2}=0.783\right)$; DMA, $\Delta, \mathrm{y}=6.782 \mathrm{e}^{0.0138 \mathrm{x}}\left(\mathrm{R}^{2}=0.863\right)$; AsBe, $*, \mathrm{y}=3.558^{\mathrm{e}-0.00231 \mathrm{x}}\left(\mathrm{R}^{2}=0.790\right)$; Extract, $\mathbf{\square}$, $\mathrm{y}=104.37 \mathrm{e}^{-0.00600 \mathrm{x}}\left(\mathrm{R}^{2}=0.940\right) ; \mathrm{T}-A s, \square, \mathrm{y}=351.42 \mathrm{e}^{-0.0117 \mathrm{x}}$ $\left(\mathrm{R}^{2}=0.988\right)$ 


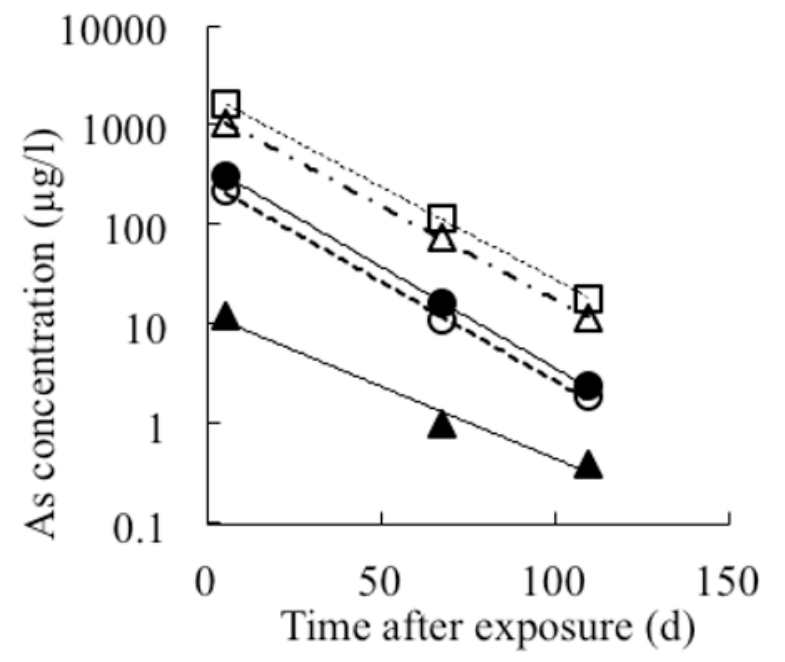

Fig. 4. Changes of arsenic species concentration in urine after discharge.

$$
\begin{aligned}
& \text { AsV, } \mathbf{\Lambda}, \mathrm{y}=13.1 \mathrm{e}^{0.033 \mathrm{x}}\left(\mathrm{R}^{2}=0.9776\right) ; \text { AsIII, o, } \\
& \mathrm{y}=279.7 \mathrm{e}^{-0.046 \mathrm{x}}\left(\mathrm{R}^{2}=0.9980\right) ; \text { MMA, } \bullet, \mathrm{y}=414.69 \mathrm{e}^{-0.047 \mathrm{x}} \\
& \left(\mathrm{R}^{2}=0.9998\right) ; \mathrm{DMA}, \Delta, \mathrm{y}=1385.9 \mathrm{e}^{0.043 \mathrm{x}}\left(\mathrm{R}^{2}=0.9998\right) ; \mathrm{T}-\mathrm{As}, \\
& \square, \mathrm{y}=2121.9 \mathrm{e}^{-0.043 \mathrm{x}}\left(\mathrm{R}^{2}=0.9998\right)
\end{aligned}
$$

T-As in urine of the first sample was $1607.2 \mu \mathrm{g} / 1$ but Ga was not detected $(<0.14 \mu \mathrm{g} / \mathrm{l})$. The AsV, AsIII, and MMA concentrations were 7, 41, and 51 times higher than those of reference values of $1.7,5.4$, and $6.2 \mu \mathrm{g} / 1$ obtained in our previous study (Suzuki et al., 2009), respectively. After discharge, he took a 10-day holiday and moved to a factory with no arsine so his As concentrations had decreased to close to the reference levels by 68 days after exposure. At 110 days, all of the As compound concentrations were at very low levels that were comparable with the reference levels. The BHTs of urinary AsIII, AsV, MMA, and DMA were estimated to be 14.6, 20.0, 14.3 and 15.5 days, respectively.

\section{Conclusion}

The toxicity profile of exposure to arsine metabolites is considered to be the same as that of inorganic arsenic exposure. Possible effects due to iAs toxicity should be considered in arsine exposure.

\section{Acknowledgements}

This work was supported by a Health and Labour Sciences Research Grant (23250301) from the Japanese Ministry of Health Labour and Welfare, and Grant-inAids for Scientific Research (22590123, 23390165, 23590754) from the Japan Society for the Promotion of Science.

\section{References}

Apostoli P, Alessio L, Romeo L, Buchet JP, Leone R. Metabolism of arsenic after acute occupational arsine intoxication. J Toxicol Environ Health 1997; 52: 331-342.

Hesdorffer CS, Milne FJ, Terblanche J, Meyers AM. Arsine gas poisoning: the importance of exchange transfusions in severe cases. Br J Ind Med 1986; 43: 353-355.

Dakeishi M, Murata K, Grandjean P. Long-term consequences of arsenic poisoning during infancy due to contaminated milk powder. Environ Health 2006; 5: 31 .

Le XC, Cullen WR, Reimer KJ. Human urinary arsenic excretion after one-time ingestion of seaweed, crab, and shrimp. Clin Chem 1994; 40: 617-624.

Suzuki Y, Shimoda Y, Endo Y, Hata A, Yamanaka K, Endo G. Rapid and effective speciation analysis of arsenic compounds in human urine using anionexchange columns in HPLC-ICP-MS. J Occup Health 2009; 51: 380-385.

Higashikawa Y, Kazui Y, Suzuki S, Ohtsuru O. Arsenic speciation of arsine-exposed blood samples by high-performance liquid chromatographyinductively coupled plasma mass spectrometry and as-adduct, a possible indicator of $\mathrm{AsH}_{3}$ exposure. J Anal Toxicol 2008; 32: 344-348.

Yoshino Y, Yuan B, Miyashita SI, Iriyama N, Horikoshi A, Shikino O, et al.. Speciation of arsenic trioxide metabolites in blood cells and plasma of a patient with acute promyelocytic leukemia. Anal Bioanal Chem 2009; 393: 689-697. 